\title{
The effect of irrelevant cues and overtraining on discrimination reversal in the pigeon'
}

GEORGE MARSH ${ }^{2}$ AND RICHMOND JOHNSON, DEPARTMENT OF PSYCHOLOGY, LEHIGH UNIVERSITY, Bethlehem, Pa. 18015

A discrimination reversal was learned more slowly when the same irrelevant cues were present during both original learning and reversal than when they were present only during reversal. No overtraining reversal effect was obtained.

The purpose of the present research was to determine the effect of irrelevant cues and overtraining on the speed of discrimination reversal. According to many two-stage theories of discrimination learning (e.g., Sutherland, 1959; Zeaman \& House, 1963; Lovejoy, 1966) the speed of discrimiration reversal depends upon the strength of mediating "attentional" responses to the stimulus dimension relevant in original learning and reversal. Shepp \& Turissi (1966) have hypothesized that the presence of irrelevant visual cues during training is a necessary component for conditioning these mediating responses. If this is true then the presence of irrelevant visual cues during original learning should facilitate reversal learning.

This result would also be predicted by Harlow's (1959) or Restle's (1955) theory because the irrelevant cues represent "error factors" which will have been adapted out during original learning and thus will be non-functional as sources of interference during reversal learning. According to both types of theory the effect of overtraining should be to produce an increase in the speed of reversal learning (overtraining reversal effect-ORE).

Design. The design was a 2 by 2 factorial with the two factors being the presence or absence of irrelevant cues during original learning and training to criterion vs overtraining. All groups had the irrelevant cues present during reversal learning.

Subjects. The Ss were 20 experimentally naive Silver King pigeons approximately 8-10 weeks old at the beginning of the experiment and were maintained at $75 \%$ of their ad lib body weight throughout the experiment.

Apparatus. The apparatus was double key Skinner box for pigeons. All the experimental events were programmed automatically by equipment housed in a room adjacent to the $\mathrm{Ss}$ chamber.

Procedure. The Ss were magazine trained and shaped to key peck over two days of pretraining with a key illuminated by a white light. Then 10 Ss were randomly assigned to either the constant or irrelevant training conditions. In the constant condition the relevant cues were black horizontal or vertical stripes on a white background projected onto the keys by in-line read-out devices. In the irrelevant condition the relevant cues were the same but in addition the background color (red or green) was varied within trials and was irrelevant.

The discrimination was a simultaneous, response terminated, discrete trial procedure. The spatial position of the stimuli varied randomly and the positive cue (horizontal or vertical stripes) was randomly assigned to each $S$. The stimuli were presented for a maximum of $15 \mathrm{sec}$ or were terminated by an S's response. The trials were separated by a $10 \mathrm{sec}$ blackout period. Following a correct response the $S$ received a reinforcement consisting of a 4 sec access to mixed grain from a food magazine. The Ss were given 100 trials per day until they reached a criterion of $90 \%$ correct within a single day.

Table 1

\begin{tabular}{lcccc}
\multicolumn{1}{c}{ Groups } & \multicolumn{2}{c}{ Constant } & \multicolumn{2}{c}{ Irrelevant } \\
& Criterion & Overtrained & Criterion & Overtrained \\
\hline $\begin{array}{l}\text { Mean errors } \\
\text { to criterion in } \\
\text { original learning }\end{array}$ & 60.0 & 52.4 & 139.2 & 115.0 \\
$\begin{array}{l}\text { Mean errors to } \\
\text { criterion in } \\
\text { reversal }\end{array}$ & 159.0 & 181.4 & 355.8 & 353.6 \\
\hline
\end{tabular}

Upon reaching criterion the $S s$ were matched on number of days to criterion and then randomly assigned to a group reversed at criterion or given $\mathbf{5 0 0}$ trials of overtraining prior to reversal. The Ss were run on the reversal until they met the same criterion used in original learning.

Results. The mean number of errors to criterion during original learning and reversal learning are shown in Table 1 . A 2 by 2 factorial analysis of variance on the number of errors during original learning showed that the main effect for the constant vs irrelevant cues was significant $(F=19.48$, df $=1,16, p<.001)$. The main effect for criterion vs overtraining was not significant $(F<1)$, nor was the interaction $(F<1)$ indicating successful matching of the training groups.

An analysis of the errors to criterion during reversal showed that the main effect for the constant vs irrelevant cues was significant $(F=10.79$, df $=1,16, p<.01)$. The main effect for criterion vs overtraining was not significant $(F<1)$ nor was the interaction $(F<1)$. The level of performance in the two overtraining groups was above $90 \%$ correct during the 500 trials of overtraining.

Discussion. The finding that an irrelevant visual cue retards learning during original learning is consistent with Restle's (1955) theory which states that the rate of learning is a function of the proportion of relevant cues in the problem. That the same effect should be found during reversal learning with irrelevant visual cues present is inconsistent with the hypotheses described previously. If the speed of learning a reversal is a function of the mediating responses conditioned during original learning it does not appear that irrelevant visual cues are necessary for the conditioning of these mediating responses as hypothesized by Shepp \& Turissi (1966). The Ss in the constant groups also had no opportunity to adapt out these irrelevant cues during original learning and yet they learned the reversal significantly faster than the group which did have irrelevant cues present during training.

The authors have no ready explanation for this surprising result. Perhaps the mediating "attentional" responses are conditioned more rapidly when they are not subject to competition from irrelevant cues during training. The constant groups experienced the irrelevant cues for the first time during reversal. Although novel irrelevant cues have often been found to have a high "attention" value it may be that the introduction of novel cues during reversal reduces the amount of negative transfer. Additional studies are needed to investigate these possibilities.

The failure to find an ORE in the present study is consistent with the results of a number of other studies employing strong irrelevant cues (D'Amato, 1965; Hirayoshi \& Warren, 1967; Schade \& Bitterman, 1965; Uhl, 1964).

On the other hand Mackintosh (1963) found an equivalent ORE in his group presented with an irrelevant visual cue during original training and in the group in which the irrelevant visual cue was absent during original training but was introduced during reversal. Williams (1967) obtained an ORE with pigeons in a color discrimination in which no inelevant visual cues were present during original training or reversal.

It therefore appears that the presence or absence of irrelevant visual cues during original learning is not a critical variable in obtaining an ORE.

\section{REFERENCES}

D'AMATO, M. R. The overlearning reversal effect in monkeys provided a salient irrelevant dimension. Pyychon. Sci, 1963, 3, 21-22.

HARLOW, H. F. Learning set and error factor theory. In S. Koch (Ed.), Pyychology: a study of a science. Vol. 2, New York: McGraw-Hin, 1959. Pp. 492-537.

HIRAYOSHI, I., \& WARREN, J. M. Overtraining and reversal by experimentally naive kittens. J. comp. physiol. Prychol, 1967,64, 507-510.

LOVEJOY, E. Analysis of the avertearning reversal effect. Psychol. Rev., $1966,73,87-103$.

MACKINTOSH, N. S. The effect of irrelevant cues on reversal learning in the rat. Brit. J. Prychol, 1963, 54, 127-134.

RESTLE, F. A theory of discrimination learning. Psychol Rev., 1955, 62, 11-19.

SCHADE, A. F., \& BITTERMAN, M. E. The relative difficulty of reversal and 
dimensional shifting as a function of overlearning. Psychon. Sci, 1965, 3, 28.3-284.

SHEPP, B. E., \& TURRISI, F. D. Learning and transfer of mediating responses in discriminative learning. In N. R. Ellis (Ed.), Int. Rev. of Res. men. Retard., Vol. 2, New York: Academic Press, 1966. Pp. 85-121.

SUTHERLAND, N. S. Stimulus analyzing mechanisms. In Proceedings of a symposium on the mechanization of the thought processes. Vol. II. London: Her Majesty's Stationary Office, 1959. Pp. 575-609.

WLLLAMS, D. I. The overtraining reversal effect in the pigeon. Psychon. Sci, 1967, 7, 261-262.

UHL, C. N. Effects of overtraining on reversal and nonreversal discrimination shifts. Percept. mot. Skills, 1964, 19, 927-934.
ZEAMAN, D., \& HOUSE, B. J. The role of attention in retardate discrimination learning. In N. R. Ellis (Ed.), Handbook of mental deficiency. New York: McGraw-Hill, 1963.

\section{NOTES}

1. This research was supported in part by Grant No. MH 18104-01 from NIMH to the first author. A preliminary report of experiment was presented at the meetings of the Eastern Psychological Association in Washington, D. C. in April, 1968. The authors would like to acknowledge the assistance of George Walz in running some of the Ss.

2. Now at Southwest Regional Laboratories, 11300 La Cienega Blvd., Inglewood, California. 